\title{
The ecological determinants of baboon troop movements at local and continental scales
}

\author{
Caspian Johnson ${ }^{1 *}$, Alex K Piel ${ }^{2}$, Dan Forman ${ }^{1}$, Fiona A Stewart ${ }^{2}$ and Andrew J King ${ }^{1}$
}

\begin{abstract}
Background: How an animal moves through its environment directly impacts its survival, reproduction, and thus biological fitness. A basic measure describing how an individual (or group) travels through its environment is Day Path Length (DPL), i.e., the distance travelled in a 24-hour period. Here, we investigate the ecological determinants of baboon (Papio spp.) troop DPL and movements at local and continental scales.

Results: At the continental scale we explore the ecological determinants of annual mean DPL for 47 baboon troops across 23 different populations, updating a classic study by Dunbar (Behav Ecol Sociobiol 31: 35-49, 1992). We find that variation in baboon DPLs is predicted by ecological dissimilarity across the genus range. Troops that experience higher average monthly rainfall and anthropogenic influences have significantly shorter DPL, whilst troops that live in areas with higher average annual temperatures have significantly longer DPL. We then explore DPLs and movement characteristics (the speed and distribution of turning angles) for yellow baboons (Papio cynocephalus) at a local scale, in the Issa Valley of western Tanzania. We show that our continental-scale model is a good predictor of DPL in Issa baboons, and that troops move significantly slower, and over shorter distances, on warmer days. We do not find any effect of season or the abundance of fruit resources on the movement characteristics or DPL of Issa baboons, but find that baboons moved less during periods of high fruit availability.

Conclusion: Overall, this study emphasises the ability of baboons to adapt their ranging behaviour to a range of ecological conditions and highlights how investigations of movement patterns at different spatial scales can provide a more thorough understanding of the ecological determinants of movement.
\end{abstract}

Keywords: Day path length, Baboon, Papio cynocephalus, Season, Space-use, Ranging, Modelling, Speed, Turning angle, Human-modified habitat, Movement characteristics, Comparative analysis

\section{Background}

A simple, but revealing measure of an animal's space use is the distance it moves within a 24-hour period. This distance is described as the Day Path Length (DPL). The simple parameters required to quantify DPL make it easily transferable and applicable to terrestrial and/or arboreal animals $[1,2]$, thus affording comparative investigations of DPL across species. For example, DPLs provide the basis of analyses of mammalian day range [3], and some of the most comprehensive studies of what determines how far animals travel have been undertaken on primates [4]. Like most mammals, primate ranging behaviours are primarily influenced by the distribution and abundance of essential

\footnotetext{
* Correspondence: caspianjohnson@gmail.com

${ }^{1}$ Department of Biosciences, College of Science, Swansea University, Swansea, UK

Full list of author information is available at the end of the article
}

resources [4-6], specifically food [7], but a suite of other factors are also important.

In general, primates tend towards an energy maximising strategy [8] whereby, in response to low food availability, they increase their DPLs in search of higher quality food items [9-13]. Since plant biomass and net plant productivity can be reliably inferred from rainfall data $[14,15]$, especially in seasonal habitats [16], rainfall can be used as an indirect measure of food resources and predicts primate DPLs $[7,17]$. Similarly, recent studies have demonstrated that remotely sensed data, particularly the normalized difference vegetation index (NDVI), provides an adequate measure of photosynthetic activity and, therefore, vegetation structure [18], which can hence be used to further understand primate movement ecology [19]. Increasing primate group sizes also results in longer DPLs [20] since 
larger groups experience greater intragroup feeding competition [21] and exhaust food patches quicker, forcing more frequent travel between patches [21-23]. Note, however, that primates with a more leaf-based and herbaceous diet lessens the effect of group-size on DPLs because the spatial-temporal distribution of leaves is more homogenous (e.g. Brachyteles arachnoides hypoxanthus, [24]; Colobus badius tephrosceles, [5]; Gorilla spp., [25,26]).

Baboons (Papio spp.) range throughout sub-Saharan Africa, across a multitude of habitat types making them the most widespread African primate genus [27] and perhaps coincidentally, are one of the best studied primates, particularly with respect to DPL. Numerous studies have shown that baboon DPLs respond to extrinsic changes in biotic and abiotic factors, attributed to the highly seasonal environments in which they live [9-13], and also to intrinsic social factors $[11,28]$. Accordingly, baboon troop DPLs across their range can be reliably predicted by group size and rainfall, as shown by a classic study by Dunbar in 1992 [29].

Since Dunbar's original study [29] there have been further studies of the climatic determinants of foraging and ranging behaviour in baboons (e.g. [30-32]), and new data on baboon DPL and ecology now exist. We therefore revisit the question of what determines baboon troop DPLs at a continental scale with the addition of 29 data points (DPLs) taken from recent literature, whilst considering additional ecological variables. We adopt a mixed modelling/model selection approach instead of the stepwise linear regression approach used originally [29], and also consider the potential impact of anthropogenic influence, primate species number, and NDVI. We consider anthropogenic influence because where baboons rely on predictable and high-quality food sources (e.g. crops or food/waste) that occur in human modified habitats (e.g. [20-22]), DPLs are found to be reduced and not predicted well by models that include rainfall and group size as predictors [33]. We consider primate species number on the basis that a high number of primate species may result in increased levels of inter-specific competition, which is known to drive longer DPLs, especially in frugivorous primates (e.g. $[20,21,30,34])$. Additionally, as a more recent technological development, not available to Dunbar in his 1992 study, we also consider NDVI data as it provides a good proxy for photosynthetic activity and vegetation structure for study sites [19,35].

Our understanding of the ecological determinants of baboon day path lengths at a finer (local) scale comes primarily from arid savannah habitats [9,36-40], even when considering more recent studies on the topic $[13,22,33,41-46]$. To provide a fuller analysis of the ecological determinants of movement at a local scale, and to complement our continental scale analyse (see above), we investigated the daily movements of two troops of yellow baboons, Papio cynocephalus, inhabiting the primate-rich, seasonal, and predominantly woodland habitat of the Issa Valley in Ugalla, western Tanzania. This represents the first study of baboons in this region. We begin by exploring how well our inter-population model predicts DPLs for the Issa baboons, and then go on to consider what local ecological factors predict variation in DPLs and movement characteristics.

Variation in food resources are predicted to have a large effect on baboon space use. The proportion of fruit-based versus leaf-based forage in the diet, in particular, can have a large effect upon day ranges, with DPL increasing with the quantity of fruit in the diet [4]. Since fruit tends to grow ephemerally in small, finite patches, which are distributed heterogeneously, it is quickly exhaustible $[23,47]$ and necessitates longer DPLs. Reliance on high-quality fruit can also drastically alter movement characteristics to maximise efficiency [21] and primates foraging on fruit show faster [48], straighter, and more goal-directed movement characteristics [49-51]. In contrast, leaf-based and herbaceous foods have a more homogeneous distribution in space and time [26] affording shorter DPLs and slower, more tortuous movement $[52,53]$. Regardless of food type, food abundance is dependent upon local, temporal variation in climate [16,54], and when food is scarce, individuals typically increase their DPLs in search of these food items (e.g. Papio hamadryas, [43]; Papio anubis, [12]; Eulemur rubriventer and Eulemur fulvus rufus, [55]; Gorilla gorilla, [56]; Rhinopithecus sp., [57]; Colobus satanas, [58]; Cercocebus galeritus, [59]). We therefore expected the baboons at Issa to demonstrate slower, less direct travel, and an increased DPL in times of reduced fruit availability [9-13].

Other climatic variables can also directly influence primate, and specifically baboon, ranging behaviour. If temperatures are too low, or too high, for example, primates reduce time spent travelling in order to conserve energy (e.g. Rhinopithecus bieti, [60]; Papio ursinus, [61]). Thus, ambient temperature can be an important climatic constraint on primate ranging behaviour, and we therefore tested the prediction that the baboons DPLs will be constrained by maximum daily temperatures in the warm Tanzanian climate, resulting in slower movement [32] and reduced DPL [61]. Finally, given that Issa's baboons experience distinct wet and dry seasons, we also tested for any effect of season that might have additional and independent effects upon DPLs and movement characteristics because, for example, the availability of water sources change [9].

\section{Methods}

\section{Continental scale}

Data collection

For our continental scale analysis we used data provided in Dunbar's (1992) study [29] and updated this with DPLs 
of 29 more recent studies from the literature (see Additional file 1). If data were available for more than one group at a study site, we use each troop's DPL, and we collected information on the rate at which troop locations were taken throughout the day, i.e. sampling frequency, and whether annual mean DPL was calculated from $>12$ months study, $<12$ months, or if this was unknown, i.e. sample size. This enabled us to test for/control for any potential effect of differences in how annual mean DPL were estimated across studies in our analyses. We also collected information on troop size, anthropogenic influence (whether or not the diet of the troop was supplemented by human derived foods [yes/no]) and the number of primate species occurring at each study site. Nocturnal primates were included in the primate species count so as to account for any indirect competition that may result from their spatial overlap with the baboons. These ecological data for each study site are summarised in Table 1, and troop specific data on group sizes and DPLs are summarised in Additional file 1.

In keeping with previous comparative studies (e.g. [29$32,62]$ ), we investigated the effect of the following climate variables on mean annual DPL: mean annual temperature (Tann), mean annual rainfall (Pann), variation (standard deviation) in monthly temperature (TmoSD), variation (standard deviation) in monthly rainfall (PmoSD), the number of months per year with less than $100 \mathrm{~mm}$ of rainfall $(\mathrm{P}<100)$, and the primary productivity index (PPI: the number of months in the year where rainfall was more than twice the average annual temperature). PPI is a useful measure of productivity during the growing season in tropical habitats and is therefore a useful index of seasonality

Table 1 Ecological data for the 23 baboon populations used in the DPL continental comparison model

\begin{tabular}{|c|c|c|c|c|c|c|c|}
\hline Species \& study site & Latitude & Longitude & Altitude & \#Study troops & \#Primate Spp. & Anthropogenic influence? ${ }^{1}$ & References $^{2}$ \\
\hline \multicolumn{8}{|l|}{ Papio anubis } \\
\hline Bole, Ethiopia & 9.42 & 38.00 & 1700 & 1 & 4 & No & {$[80]$} \\
\hline Budongo, Uganda & 1.93 & 31.67 & 700 & 1 & 7 & No & [113] \\
\hline Chololo, Kenya & 0.40 & 36.95 & 1660 & 1 & 2 & No & {$[79]$} \\
\hline Gashaka Gumti, Nigeria & 7.51 & 11.61 & 320 & 2 & 9 & Yes $(1 / 2)$ & {$[114]$} \\
\hline Gilgil, Kenya & -0.49 & 36.32 & 1770 & 1 & 1 & No & {$[12]$} \\
\hline Ishasha, Uganda & -0.62 & 29.66 & 950 & 1 & 4 & No & [115] \\
\hline Metahara, Ethiopia & 8.91 & 39.93 & 950 & 1 & 2 & No & [116] \\
\hline Mulu, Ethiopia & 9.30 & 40.83 & 1275 & 1 & 2 & No & (Dunbar, unpublished) \\
\hline \multicolumn{8}{|l|}{ Papio cynocephalus } \\
\hline Amboseli, Kenya & -2.64 & 37.25 & 1130 & 6 & 3 & Yes $(1 / 6)$ & {$[17,33,117]$} \\
\hline Mikumi, Tanzania & -7.09 & 37.42 & 550 & 1 & 5 & No & {$[77]$} \\
\hline Tana, Kenya & -1.93 & 40.14 & 30 & 1 & 6 & No & {$[118]$} \\
\hline Issa, Tanzania* & -5.51 & 30.56 & 1600 & 2 & 6 & No & This study \\
\hline \multicolumn{8}{|l|}{ Papio hamadryas } \\
\hline Awash, Ethiopia & 8.84 & 40.01 & 950 & 5 & 2 & No & {$[43,45,119]$} \\
\hline Erer-Gota, Ethiopia & 9.56 & 41.38 & 1200 & 1 & 1 & No & {$[120]$} \\
\hline \multicolumn{8}{|l|}{ Papio papio } \\
\hline Mt. Assirik, Senegal & 12.87 & -12.80 & 150 & 2 & 6 & No & {$[38]$} \\
\hline \multicolumn{8}{|l|}{ Papio ursinus } \\
\hline Blouberg, SA & -23.03 & 29.06 & 900 & 1 & 3 & No & (Noser, unpublished) \\
\hline Cape Point, SA & -34.27 & 18.43 & 50 & 10 & 1 & Yes $(7 / 10)$ & {$[13,39,121]$} \\
\hline Drakensberg, SA & -29.47 & 29.26 & 2250 & 2 & 1 & No & {$[41,122]$} \\
\hline Honnet, SA & -22.63 & 30.18 & 310 & 2 & 2 & Yes $(1 / 2)$ & {$[61]$} \\
\hline Mkuzi, SA & -27.60 & 32.05 & 125 & 1 & 2 & No & [42] from [123] \\
\hline Suikersbosrand, SA & -26.50 & 28.22 & 1600 & 1 & 2 & No & {$[124]$} \\
\hline Tsaobis, Namibia & -22.55 & 15.73 & 1000 & 1 & 1 & No & {$[44]$} \\
\hline DeHoop, SA & -34.43 & 20.57 & 10 & 2 & 1 & No & (Hill, unpublished) \\
\hline Mt. Zebra, SA & -32.20 & 25.39 & 1500 & 1 & 1 & No & [125] from [123] \\
\hline
\end{tabular}

${ }^{1}$ Indicates whether baboons studied experience anthropogenic influences, and if so, how many troops. ${ }^{2}$ Unpublished data are acquired from authors listed. 
$[62,63]$. These climate data were taken from the original studies and/or Dunbar's (1992) study [29]; where this information was not available, we followed the methods provided in Bettridge et al. [31] and used data from the Willmott \& Matsuura [64] meteorological database. This database provides a global dataset of annual and monthly temperatures and rainfall in grids of $0.5^{\circ}$ latitude by longitude, which are derived from a combination of Legate and Willmott's $[65,66]$ weather station records and the Global Historical Climatology Network (version 2). We calculated average values across all data points in the Willmott \& Matsuura dataset that fell within $0.5^{\circ}$ latitude and longitude to the relevant site. All temperatures are provided in ${ }^{\circ} \mathrm{C}$, and rainfall in $\mathrm{mm}$. We also collected remotely sensed information on NDVI, since it is a well-established measure of photosynthetic activity and vegetation structure [18] with proven applications in understanding species' ecology $[19,35]$. NDVI data was retrieved for an area of $10.25 \mathrm{~km}^{2}$ for each study site from the Oak Ridge National Laboratory Distributed Active Archive Centre (http://daac.ornl.gov/MODIS/) and a 14-year average for each site was calculated from the available MOD 13Q1 data set (2000-2014). All climate data for each specific baboon study site are summarised in Table 2 .

Table 2 Climate and environmental data for $\mathbf{2 3}$ baboon study populations

\begin{tabular}{|c|c|c|c|c|c|c|c|}
\hline Species \& study site & Pann & PmoSD & Tann & TmoSD & PPI & $P<100$ & NDVI \\
\hline \multicolumn{8}{|l|}{ Papio anubis } \\
\hline Bole, Ethiopia & 1105 & 85.75 & 19.50 & 1.30 & 8.0 & 8.0 & 0.47 \\
\hline Budongo, Uganda & 1679 & 68.18 & 22.10 & 0.75 & 10.0 & 4.5 & 0.84 \\
\hline Chololo, Kenya & 549 & 40.31 & 22.90 & 1.03 & 5.0 & 9.5 & 0.29 \\
\hline Gashaka Gumti, Nigeria & 1800 & 109.90 & 26.60 & 1.00 & 8.0 & 5.0 & 0.38 \\
\hline Gilgil, Kenya & 595 & 20.95 & 18.10 & 0.69 & 5.0 & 11.0 & 0.46 \\
\hline Ishasha, Uganda & 1292 & 37.87 & 22.00 & 0.93 & 10.0 & 6.0 & 0.68 \\
\hline Metahara, Ethiopia & 639 & 58.99 & 24.50 & 1.56 & 6.0 & 9.0 & 0.26 \\
\hline Mulu, Ethiopia & 1105 & 64.00 & 15.90 & 1.61 & 8.0 & 7.0 & 0.42 \\
\hline \multicolumn{8}{|l|}{ Papio cynocephalus } \\
\hline Amboseli, Kenya & 336 & 23.44 & 22.86 & 1.43 & 3.0 & 11.0 & 0.26 \\
\hline Mikumi, Tanzania & 832 & 63.27 & 25.21 & 2.72 & 6.0 & 6.0 & 0.6 \\
\hline Tana, Kenya & 803 & 49.57 & 28.00 & 1.12 & 5.0 & 9.0 & 0.72 \\
\hline Issa, Tanzania* & 1200 & 79.69 & 20.00 & 0.32 & 7.0 & 5.0 & 0.6 \\
\hline \multicolumn{8}{|l|}{ Papio hamadryas } \\
\hline Awash, Ethiopia & 639 & 49.28 & 24.62 & 1.68 & 6.0 & 8.8 & 0.28 \\
\hline Erer-Gota, Ethiopia & 665 & 59.12 & 24.20 & 1.61 & 5.0 & 9.0 & 0.32 \\
\hline \multicolumn{8}{|l|}{ Papio papio } \\
\hline Mt. Assirik, Senegal & 953.9 & 97.90 & 30.50 & 2.45 & 5.0 & 7.7 & 0.47 \\
\hline \multicolumn{8}{|l|}{ Papio ursinus } \\
\hline Blouberg, SA & 343 & 35.42 & 20.75 & 3.67 & 7.0 & 12.0 & 0.50 \\
\hline Cape Point, SA & 743 & 36.86 & 17.90 & 3.47 & 6.9 & 10.0 & 0.42 \\
\hline Drakensberg, SA & 1197 & 82.57 & 14.60 & 4.18 & 8.3 & 6.0 & 0.45 \\
\hline Honnet, SA & 307 & 45.01 & 21.33 & 3.58 & 3.0 & 10.3 & 0.29 \\
\hline Mkuzi, SA & 630 & 37.77 & 22.40 & 2.92 & 6.0 & 9.8 & 0.68 \\
\hline Suikersbosrand, SA & 700 & 44.42 & 15.95 & 4.50 & 7.0 & 9.0 & 0.56 \\
\hline Tsaobis, Namibia & 122 & 16.45 & 13.80 & 2.33 & 3.0 & 12.0 & 0.12 \\
\hline DeHoop, SA & 428 & 9.23 & 16.50 & 3.07 & 7.0 & 12.0 & 0.58 \\
\hline Mt. Zebra, SA & 343 & 16.11 & 15.00 & 4.57 & 6.0 & 12.0 & 0.32 \\
\hline
\end{tabular}




\section{Statistical analyses}

We fitted annual mean DPL as the response variable in a linear mixed model (LMM) in R (lme4 package [67], $\mathrm{R}$ version 3.1.0) to determine which of the aforementioned ecological and climatic variables best explained variation in mean baboon troop DPLs. We fitted 'population' as a random effect to control for the potential nonindependence of data from multiple troops within the same population. Co-linearity between all effects was checked using Spearman's rank correlation tests, with a cut-off criterion of $r_{s}=0.60$ [68] for including effects in the same model. We then fitted a series of models entering combinations of ecological and climate variables as continuous fixed and/or categorical fixed effects. Additional file 2 provides the top ten candidate models used to predict variation in annual mean DPL at a continental scale. To choose among models, we adopted a minimum adequate model selection procedure that considered all biologically meaningful combinations of the fixed effects described. Candidate models with the lowest Akaike information criterion (AIC) value [69] were consequently selected. Where models had AIC scores within two points of each other, both models were considered to be plausible alternatives and the model that was the most parsimonious (i.e. the model with the fewest fixed effects) was selected preferentially [70]. The significance of individual terms were then calculated from the selected model and terms not included in the selected model were put back into the model to obtain level of non-significance (lmerTest package, R: [71]).

\section{Local scale}

\section{Study site}

Local scale data was collected in the Issa valley of western Tanzania $\left(05^{\circ} 23 \mathrm{~S} 30^{\circ} 35 \mathrm{E}\right), 81 \mathrm{~km}$ East of Lake Tanganyika. The Ugalla region extends over $3352 \mathrm{~km}^{2}$ and is comprised of steep, broad valleys and flat hilltop plateaus that range in altitude from $900-1800 \mathrm{~m}$. The habitat of the study area is described as being a diverse mixture of vegetation types including swamp, dry grassland, wooded grassland, woodland, gallery forest, thicket forest, and hill forest [72].

\section{Movement data}

Movement data were collected by CJ and field assistants from January to August 2012 in accordance with the regulations of the Tanzanian Wildlife Research Institute. In total 81 days were spent tracking two troops of yellow baboons over the study period. These were Matawi Troop (MT, N = 31 group members) and Camp Troop (CT, $\mathrm{N}=22$ group members). The baboons were successfully located on 61 of these tracking days. Once found, the troop was followed until they reached a sleeping site, typically around 19:00. Observers would then return the following morning to the same place at 07:00 (before baboons left the sleeping site). This was repeated until they were lost, or a full three days of follows were completed. In total this yielded a total observation time of $546 \mathrm{hrs}$ (CT: $349 \mathrm{hrs,} \mathrm{MT:} 197 \mathrm{hrs).} \mathrm{On} \mathrm{all} \mathrm{occasions}$ the troops were followed, troop movement was recorded at 5-minute intervals, at a distance of $20-50 \mathrm{~m}$ behind the troop, using hand-held Garmin $520 \mathrm{Hcx}$ Global Positioning Systems (GPS). These GPS data were used to record the distance troops travelled from sunrise (07:00 \pm 15 mins) to sunset (19:00 \pm 30 mins) .

To calculate DPLs, distances between consecutive GPS points were calculated using the Great-Circle Equation [73]. DPL's were only calculated from full-day follows, or where the baboon locations were unknown for a period of less than 60 minutes representing a mean of 4.8 full day follows per month (CT: 3.1 days per month, MT: 1.7 days per month). Movement characteristics, as described by speed and turning angle distributions can provide information on orientation and searching behaviour [74]. Speed $(\mathrm{m} / \mathrm{min})$ and turning angle $(\theta)$ were calculated for successive GPS locations using the adehabitatLT package, R [75].

\section{Temperature and season}

An Onset H8 Pro series Hobo temperature logger was deployed in woodland plateau vegetation. This device recorded ambient temperature every 30 mins and provided minimum, maximum, and mean temperature readings daily (range: $12.5-38.7^{\circ} \mathrm{C}$; mean \pm Standard Deviation: $20.5^{\circ} \mathrm{C} \pm \mathrm{SD} 3.8^{\circ} \mathrm{C}$ : Figure 1). Rainfall was recorded using an Onset HOBO data logging rain gauge RG3-M deployed in the woodland plateau near camp. From January to July 2012, rainfall averaged $111 \pm$ SD $93 \mathrm{~mm} /$ month, range: 0-248 mm (Figure 1). There were two distinct seasons at Issa, a rainy season (November-April) and a dry season (May-September), with dry months being defined as having $<100 \mathrm{~m}$ of rainfall [72].

\section{Food availability}

Whilst baboons rely on a variety of food sources [40], fruit comprises a large portion of their diet [12,33,37-40,76-80] and is selected for when available [9]. We therefore utilised a pre-established phenology transect, that intersected the miombo woodland habitat, that was $1.7 \mathrm{~km}$ in length and $10 \mathrm{~m}$ in width and was fully contained within the home range of CT. Only woody plants known to produce fruits or seed pods that were consumed by the baboons and that were $\geq 2 \mathrm{~m}$ in height with a diameter at breast height $\geq 5 \mathrm{~cm}$ were monitored. This resulted in a total of 288 shrubs, lianas and trees from 17 species. The transect was walked every month for the duration of the study period, and the presence/absence of fruit or seed pods for each plant was noted [81]. Fruit abundance (we use this as 


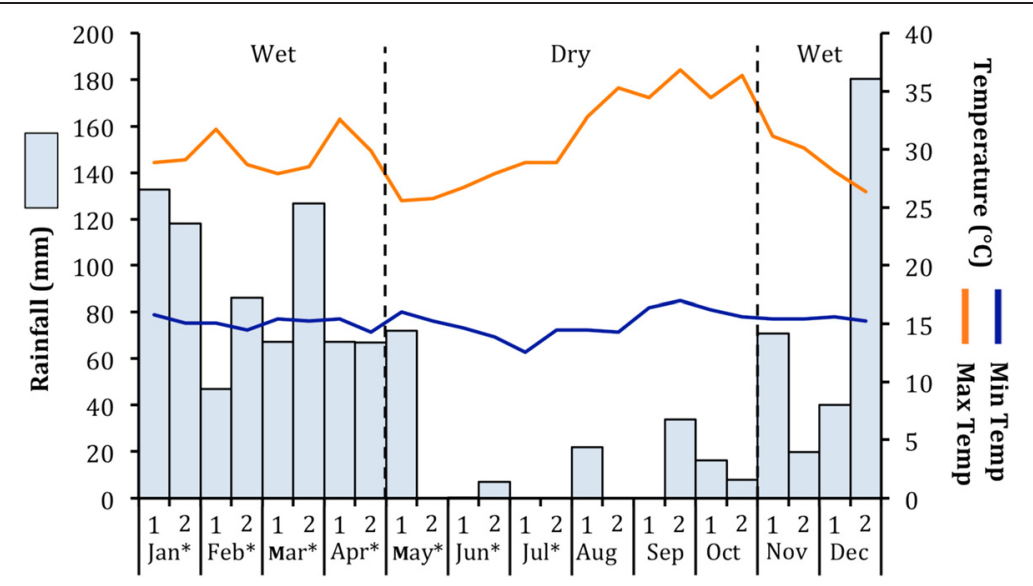

Figure 1 Issa climate. Minimum and maximum average bi-monthly temperatures and rainfall at Issa during 2012. The study period is depicted by months with an *. Months belonging to the dry season are those with $<100 \mathrm{~mm}$ of rainfall and are highlighted with dashed lines.

a proxy for fruits and seed pods combined) was then estimated with a commonly used measure, the monthly fruit abundance index $\left(\mathrm{FAI}_{m}\right)$ [82-85]:

$$
F A I_{m}=\sum_{k=1}^{n} D_{k} B_{k} P_{k m}
$$

where $\mathrm{D}_{k}$ is the density of species $k$ per $\mathrm{km}^{2}, \mathrm{~B}_{k}$ is the mean DBH of species $k$, and $\mathrm{P}_{k m}$ is the percentage of trees of species $k$ in a fruiting condition in a month $m$ (Figure 2).

\section{Statistical analyses}

To test for differences in DPLs of the two Issa troops, a Mann Whitney $U$-test was used. To investigate what

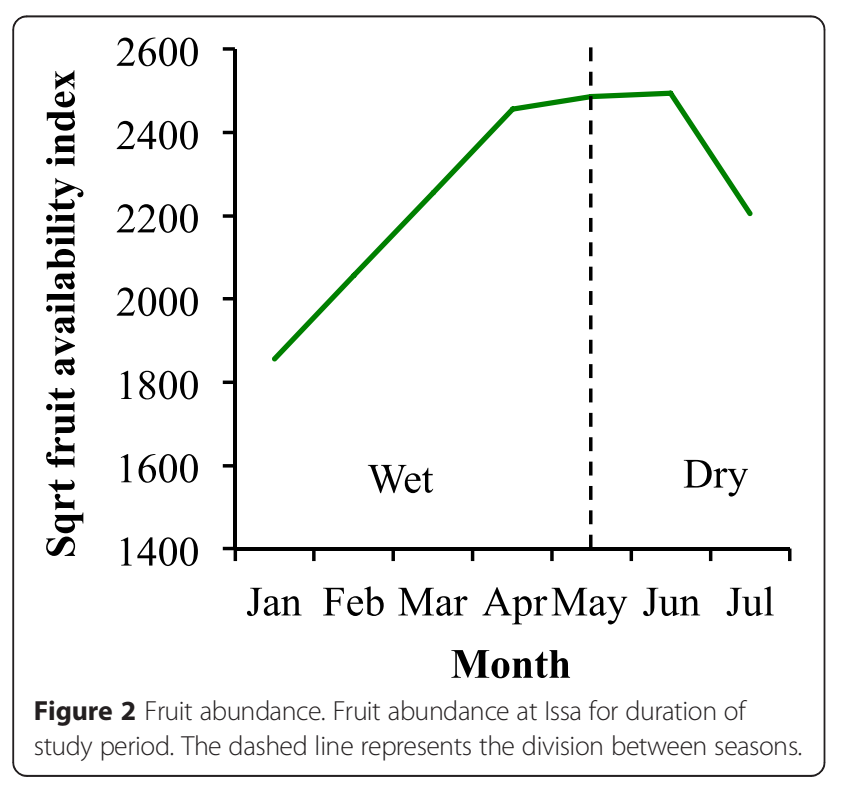

factors predicted variation DPL we used a linear model (LM) (lme4 package, R: [67]), with normal error structure. We fitted a series of fixed effects in accordance with our predictions. Our two continuous effects were maximum temperature $\left({ }^{\circ} \mathrm{C}\right)$ and FAI, and we fitted season (wet, dry), and troop ID as categorical effects. We used maximum temperature as a reflection of the hottest part of the day, which is most likely to constrain baboon DPL.

To test what factors predicted variation in speed and/ or distribution of turning angles we implemented generalised additive models (GAM) (mgcr package, R: [67]). We only analysed speed and turning angle data where baboons were not stationary (i.e. speed $>1 \mathrm{~m} / \mathrm{min}$ ), and randomly sub-sampled $n=10$ data points from each observation day to remove any temporal auto-correlation in our data. We then fitted maximum temperature, FAI and season (wet, dry) as fixed effects, whilst controlling for any effect of day (of study period) and troop (CT, MT). We used a GAM here rather than a standard linear model because GAMs are more capable of recognising nonlinear temporal variation [86]. The smoothed effect of time (day of study period) was based on penalized regression splines, to take into consideration the cyclic pattern of patterns of space-use.

For both our LMM (DPL analyses) and GAMs (speed, turning angle analyses) minimum adequate model selection was based on a procedure that considered all biologically meaningful combinations of fixed effects. The best model was subsequently selected by the lowest AIC value [69], but models within two AIC points were considered to be plausible alternatives and the model that was the most parsimonious (i.e. the model with the fewest fixed effects) was selected preferentially [70]. The significance of the individual terms was then calculated from the selected model and all dropped terms were put 
back into the model to obtain the level of non-significance (lmerTest package, R [71]).

\section{Results and Discussion}

\section{Continental scale}

Our analysis of the effects of ecological and biological variables on DPLs at a continental scale indicates that mean DPLs for 47 baboon troops across 23 different populations were best explained by a model that considered the independent effects of mean monthly rainfall, mean annual temperature, and anthropogenic influence (Table 3; Figure 3 and see Additional file 2 for best candidate models). All other fixed effects tested did not significantly predict variation in annual mean DPL (Table 3 ). We discuss each of the main effects in turn.

With higher mean monthly rainfall we found shorter baboon DPLs. As higher levels of precipitation typically result in more productive habitats and therefore more food $[15,16]$, troops should encounter food more frequently and thus travel shorter distances at sites that experience high rainfall [9]. A more direct measure of vegetation (NDVI) did not, however, predict annual mean DPL. One possible reason for this might be because of baboons reliance on surface water, that they require on a daily basis [17], and whilst NDVI may represent "better" quality habitat, it does not necessarily reflect water availability, which might act as a constraint on baboon movement. We also found that baboons in hotter habitats travel further than those in cooler habitats. If the relationship between temperature and DPL in this case were causal, we would expect baboons to travel less far in hotter habitats, due to enforced rest as a result of thermal loading [87]. Instead, it is likely that higher ambient temperatures reflect more arid and therefore less productive environments with less surface water [88]. We therefore interpret the positive effect of hotter environments on annual mean DPL to be a consequence of variance in productivity and surface water across sites. Given the significance of annual temperature and monthly rainfall at this scale, it would be instructive to gather information on the availability of drinking sites/surface water in future work to quantify directly the importance of this resource in determining baboon DPL. We also found that DPLs were shorter where troops experienced anthropogenic influence. Anthropogenic influence was not considered by Dunbar [29] in his original model, but has since been highlighted as an important factor mediating DPLs $[22,33]$. This is because baboons in human-modified habitats typically have access to high quality and predictable food resources meaning baboons are able to sate their nutritional requirements within a smaller daily ranging distance, e.g. by crop-raiding and/or scavenging human foods $[22,89-94]$.

Contrary to Dunbar [29] and our own expectations, we did not find that group size predicts variation in annual mean DPL. The negative effect of increasing group size on ranging behaviour has been well documented across the primate order $[4,95]$ and within the baboon genus $[11,28,29]$. The lack of any group size effect here might be explained by the importance of the key ecological variables retained in our final model; these appear to be far more important, perhaps reflecting the changing environments and associated increase in exposure to human-modified habitats that baboons are experiencing. The effect of human-modified habitat use has also been reported to negate the effect of group size at a local scale. In the Cape Peninsula, South Africa, Hoffman \& O'Riain [22] found that the largest group in the population $(\mathrm{N}=115)$ had a DPL that did not differ significantly from the two smallest troops (both troops $\mathrm{N}=16$ ), which was explained by their near 100\% use of human-modified habitat.

Table 3 Estimate, standard error, test statistic and P-value for compatible predictors of annual mean DPL for baboon troops at a continental scale

\begin{tabular}{|c|c|c|c|c|c|}
\hline Model term & Estimate & Standard error & $t$-value & $d f$ & $p$ \\
\hline Temperature (mean annual) & 0.24 & 0.07 & 3.61 & 1 & 0.002 \\
\hline Rainfall (mean annual) & -0.003 & 0.0007 & -4.14 & 1 & 0.0005 \\
\hline Anthropogenic influence ${ }^{1}$ & -2.04 & 0.46 & -4.39 & 1 & 0.0001 \\
\hline Sample size (months) ${ }^{2}$ & 0.34 & 0.79 & 0.44 & 2 & 0.08 \\
\hline Temperature (monthly SD) ${ }^{3}$ & 0.41 & 0.27 & 1.51 & 1 & 0.14 \\
\hline Troop size & 0.005 & 0.005 & 0.92 & 1 & 0.36 \\
\hline Altitude & -0.0006 & 0.0005 & -1.25 & 1 & 0.22 \\
\hline Sample frequency (GPS) ${ }^{4}$ & -0.03 & 0.02 & -1.65 & 1 & 0.14 \\
\hline NDVI & -0.84 & 1.89 & -0.44 & 1 & 0.66 \\
\hline
\end{tabular}

The best fitting model included those terms shown in bold text; for AIC values of the best candidate models tested see Additional file 2 .

${ }^{1}$ Categorical effect (yes, no); reference category was no anthropogenic influence. ${ }^{2}$ Categorical effect representing whether the mean DPL was calculated from $>12$ months study, $<12$ months, unknown. ${ }^{3}$ Standard deviation in rainfall across months. ${ }^{4}$ The frequency of GPS fixes taken per hour to calculate DPL. 

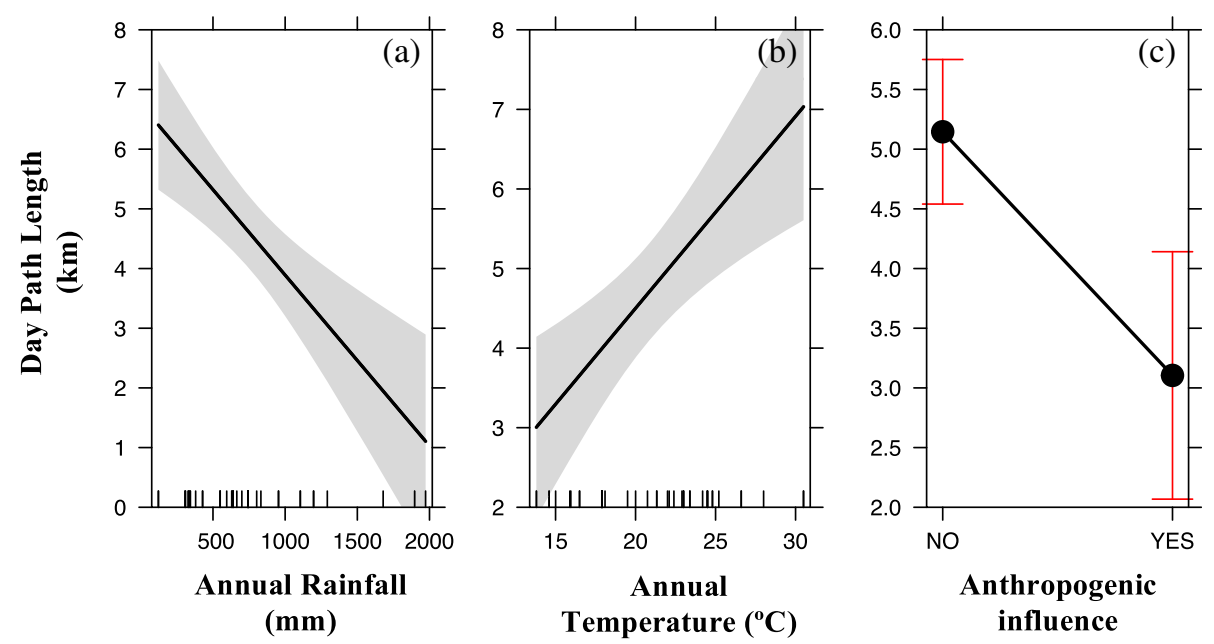

Figure 3 Predictors of DPL for $N=47$ baboon troops across Africa. Significant effects of (a) average monthly rainfall (effect[SE] $=0.04[0.01]$; $d f=1$; $p=<0.0003$ ); (b) average annual temperature (effect[SE] $=-0.23[0.06] ; \mathrm{df}=1 ; \mathrm{p}=0.001$ ); (c) Anthropogenic influence (effect[SE] $=-2.01[0.42] ; \mathrm{df}=1$; $p=0.0001$ ). Effects shown are predictions from our LMM (see Table 3) and upper and lower 95\% confidence limits are indicated by shaded areas for (a) and (b) and whiskers for (c).

\section{Local scale}

At a local scale, we found that the median DPL for CT and MT were $4.7 \mathrm{~km}$ (range: $3.1-8.5$ ) and $4.3 \mathrm{~km}$ (range: 1.5-6.0) respectively (Figure 4), and there was not a statistical difference between the DPLs of the two troops (Mann Whitney $U$-test: $\mathrm{n}_{\mathrm{CT}}=22, \mathrm{n}_{\mathrm{MT}}=12, \mathrm{P}=0.725$ ). Comparison of these observed DPLs and those DPLs predicted by the best continental-level model (see above) that considers monthly rainfall, annual temperature, and anthropogenic influence, whilst accounting for population,

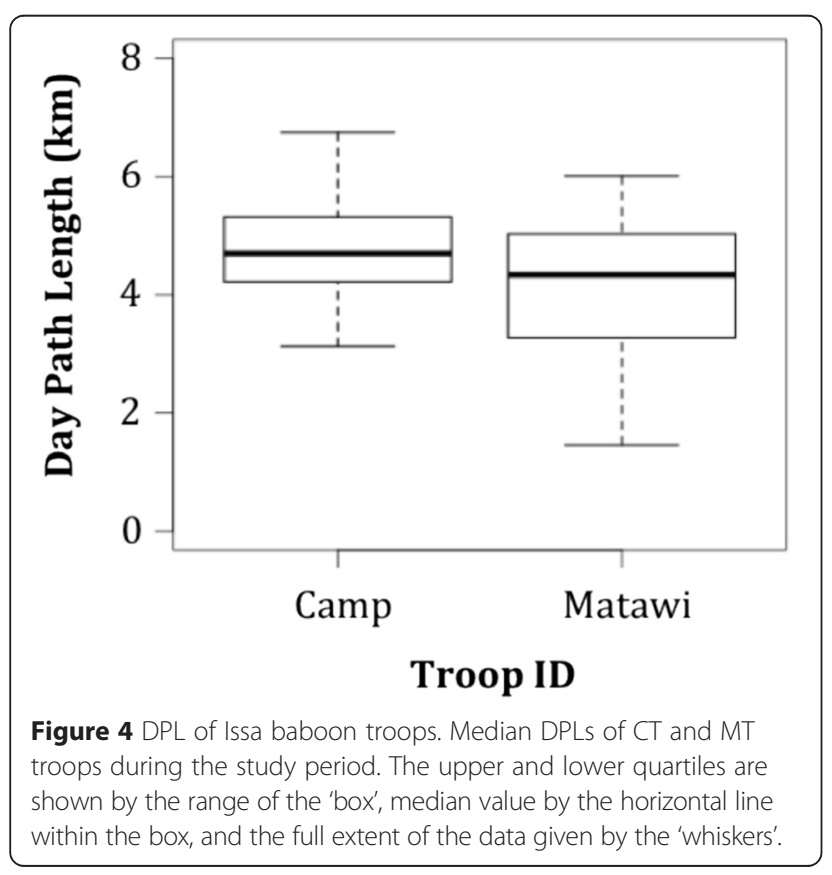

revealed that the actual DPL of Issa baboons was similar to the predicted DPL (Figure 5). Therefore, it appears that yellow baboons at Issa are not atypical and the same ecological factors that impact on baboon troop DPLs throughout their range are also good predictors of Issa troops DPLs.

Consideration of local ecological factors revealed that Issa baboon troops travelled significantly further (Table 4; Figure 6 and see Additional file 3 for best candidate models) and faster (Table 5) on cooler days. Due to the sensitivity of the vertebrate brain to even slight changes in temperature, the need for primates to regulate their internal temperature is vital [96]. In order to cool the brain, baboons dissipate heat through panting [97], however, they lack more typical mechanisms for the effective cooling of the brain (i.e. carotid rete) that are present in other similar sized, sympatric mammals [98]. This likely makes high radiant temperatures a greater challenge to their thermoregulation [98]. To avoid overheating, baboons have been observed to adjust their activity according to their thermoregulatory needs, with temperature being a negative function of activity in hot environments $[33,61,87,99]$. During periods of intense thermal loading, baboons are found to respond by seeking shade and engaging in more sedentary behaviours such as resting and grooming $[32,87,100]$. Similarly, Stelzner [99] found that travel rate in Amboseli baboons was dependent on ambient temperature at a microhabitat type level, and on hot days the baboons would slow down when traversing more shaded areas. It is plausible then, that as heat stress increases, baboons at Issa are forced into more sedentary activities, which could result in the reduced DPLs and 


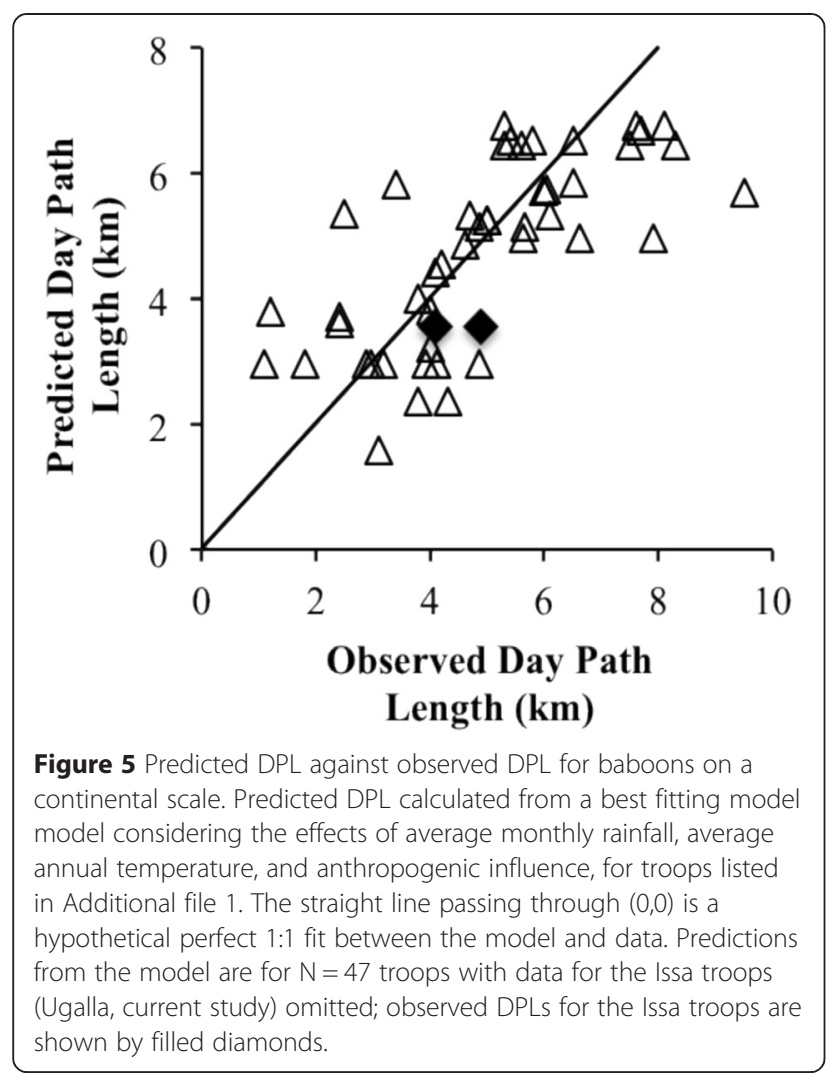

speeds we observed. Concurrent direct observations of individual and troop level behaviours would be required to confirm that Issa baboons move less on hotter days due to enforced resting.

Contrary to our expectations, we did not find FAI to significantly affect either DPL (Table 4 see Additional file 3 for best candidate models) or the movement characteristics of baboons at Issa (Table 5; Table 6). A critical influence on ranging patterns of $P$. cynocephalus is the distribution of foods [9]. In contrast with other studies $[9,10]$ local fruit abundance (here, FAI) did not significantly predict DPL (Table 4). Our finer resolution analysis of the baboon's movement characteristic similarly found no effect of FAI on speed or turning angles. This is surprising, as primates have been consistently shown to use the space in their habitats according to the learned locations of particular resources and consequently move efficiently between them [48-51]. This is especially true of fruiting trees, a core food group for baboons [12,33,37-40,76-80]. In support of this, Noser \& Byrne [101] found baboons demonstrated increased route linearity and speed when travelling to sparse, out of site, fruit patches indicating the tendency for baboons to use their space in an efficient, goal-directed way. For this reason, we expected Issa baboons to demonstrate more direct travel movements when fruit availability increases. The difference between the two studies is instructive, and highlights the need for combining behavioural (or at least basic activity data) with movement information, so that it is possible to analyse segments of travel between known resources [101]. We therefore proceeded to explore whether FAI and/or season predicted the time troops spent moving (i.e. speeds of $<1 \mathrm{~m} / \mathrm{min}$ versus $>1 \mathrm{~m} / \mathrm{min}$ ). We reasoned that time spent feeding should decrease with proportion of carbohydrate-rich fruits $[101,102]$ in the diet [30] resulting in decreased moving time as compared to other time budget variables [102]. Therefore, we expected to see less time spent moving during periods of high FAI, and our model (Additional file 4) confirmed this to be the case. Thus, whilst fine-scale movement of Issa baboons was not predicted by the availability of fruit resources, fruit availability did fundamentally alter the time they spent moving $[4,5,17]$.

We found no significant effect of season (wet, dry) on baboon DPLs or movement characteristics (Tables 4, 5 and 6), although the effect of season on the distribution of turning angles was $\mathrm{P}=0.055$ (Table 6), indicating a trend for troops' movements to become more direct during the dry season in line with our original predictions. It may be possible that the lack of any strong seasonal patterns on movement characteristics may be due to the availability of water. Baboons are obligate drinkers [9] relying heavily on surface water, the availability of which is subject to large variation in sub-Saharan Africa. Surface water is therefore an important determinant of baboon ranging patterns [37], and its availability is ultimately determined by seasonal rainfall [40] (also see above continental model). During our study period, surface water was readily available to the baboons, and so

Table 4 Estimate, standard error, test statistic and P-value for predictors of baboon troop DPL at a local scale

\begin{tabular}{|c|c|c|c|c|c|}
\hline Model term & Estimate & Standard error & $t$-value & $d f$ & $p$ \\
\hline Max. temperature & -261.8 & 75.2 & -3.48 & 1 & 0.0017 \\
\hline Fruit Abundance Index & 27.6 & 204.7 & 0.14 & 1 & 0.89 \\
\hline Season $(d r y, \text { wet })^{1}$ & -512.61 & 408.24 & -1.26 & 1 & 0.22 \\
\hline Troop ID $(C T, M T)^{2}$ & -276.18 & 405.24 & -0.68 & 1 & 0.50 \\
\hline
\end{tabular}

The best fitting model included those terms shown in bold text; for AIC values of the best candidate models tested see Additional file 3.

${ }^{1}$ Reference category was wet season. ${ }^{2} \mathrm{CT}=$ Camp Troop. MT = Matawi Troop; reference category was Camp Troop. 


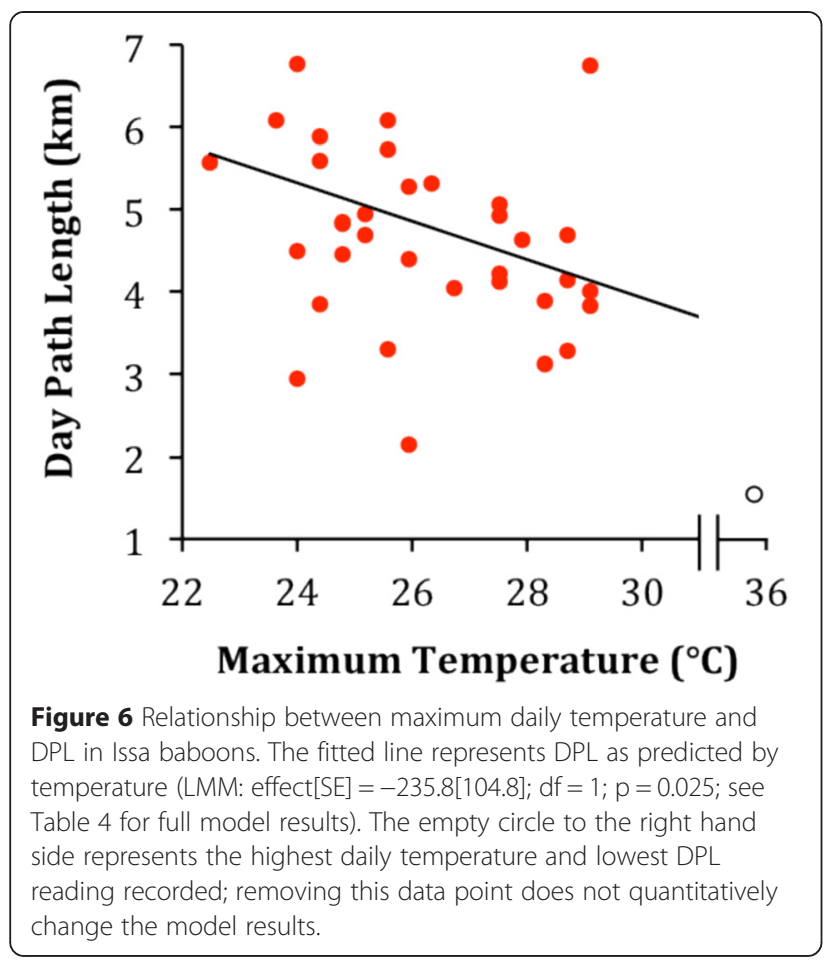

was unlikely to constrain movement paths. However, our study period did not extend through the driest months at the end of the dry season when running water at Issa becomes stagnant and gradually more confined to water holes [103]. Thus, the influence of surface water availability on ranging patterns cannot be fully determined without further study.

There may well be other key ecological factors that are important drivers of Issa baboon movements that we did not measure. For example, baboons mitigate the serious threat of nocturnal predation by utilising sleeping sites (i.e. specific sleeping trees or cliffs) $[17,104]$, and it is

Table 5 Estimate, standard error, test statistic and P-value for predictors of baboon troop travel speed at a local scale

\begin{tabular}{|c|c|c|c|c|c|}
\hline Model term & Estimate & $\begin{array}{l}\text { Standard } \\
\text { error }\end{array}$ & $\begin{array}{l}t- \\
\text { value }\end{array}$ & $d f$ & $p$ \\
\hline Max. temperature & -0.04 & 0.01 & -2.79 & 1 & 0.005 \\
\hline $\begin{array}{l}\text { Fruit Abundance } \\
\text { Index }\end{array}$ & -0.003 & 0.03 & -0.09 & 1 & 0.93 \\
\hline Season $(d r y, \text { wet })^{1}$ & 0.004 & 0.14 & 0.027 & 1 & 0.98 \\
\hline Rainfall & 0.007 & 0.005 & 1.43 & 1 & 0.16 \\
\hline Smoothing factor & & $F$ & edf & rdf & $p$ \\
\hline Day & & 0.16 & 1 & 1 & 0.69 \\
\hline
\end{tabular}

The best fitting model included those terms shown in bold text. Effect of smoothing factor is also shown with estimated degrees of freedom (edf), reference degrees of freedom (rdf), test statistic $(F)$ and $p$ value.

${ }^{1}$ Reference category was wet season.
Table 6 Estimate, standard error, test statistic and P-value for predictors of baboon troop turning angle at a local scale

\begin{tabular}{llllll}
\hline Model term & Estimate & Standard error & $\boldsymbol{t}$-value & $\boldsymbol{d f}$ & $\boldsymbol{p}$ \\
\hline Max. temperature & -0.008 & 0.009 & -0.98 & 1 & 0.33 \\
Fruit Abundance Index -0.0006 & 0.03 & -0.19 & 1 & 0.98 \\
Season (dry, wet) & -0.14 & 0.072 & -1.93 & 1 & 0.055 \\
Rainfall & -0.00009 & 0.003 & -0.04 & 1 & 0.97 \\
\hline Smoothing factor & & $\boldsymbol{F}$ & edf & rdf & $\boldsymbol{p}$ \\
\hline Day & & 1.98 & 1 & 1 & 0.16 \\
\hline
\end{tabular}

Effect of smoothing factor is also shown with estimated degrees of freedom (edf), reference degrees of freedom (rdf), test statistic $(F)$ and $p$ value.

${ }^{1}$ Reference category was dry season.

possible that the lower limit of DPL is set by the troops having to reach or travel between these sleeping sites $[13,105,106]$. Also relevant is the capacity of predation, especially by ambush predators, to influence ranging behaviour of primates [107]. Areas perceived to be 'highrisk' (vegetation allowing predators to conceal their approach) are commonly avoided by baboons [108], and leopards (Panthera pardus), the primary predator of baboons [109], were encountered frequently at Issa [110]. Their impact on the movement ecology of Issa baboons may be significant [107], and this offers yet another interesting area for future research.

\section{Conclusions}

Overall, this study emphasises the ability of baboons to adapt their ranging behaviour to extrinsic variables [111], and provides much needed data on baboon spaceuse from a woodland context. This adaptability is reflected, at least in part, by the ubiquity of baboons across a multitude of ecological and climatological contexts throughout sub-Saharan Africa (e.g. from the forests of Gombe in Tanzania, to the deserts of Tsaobis in Namibia). At a continental scale, we demonstrate the importance of including the role of human derived food sources in predicting the ranging patterns of baboons [22]. Humanderived foods are becoming increasingly available to baboons as the distinction between "wild" and "human" landscapes becomes blurred [112], and this factor, it seems, has a stronger effect upon variance in DPLs than group size, for example [29]. Moreover, this study highlights how investigations of movement patterns at different spatial and temporal scales can provide a fuller analysis of the ecological determinants of movement. Sitespecific considerations in particular are important, for example, temperature. At a continental scale, baboons in hotter places travel further, whilst baboons on a local scale travel less far on hotter days. In this instance, we find the role of temperature changes depending on the spatial scale at which it is investigated. 


\section{Additional files}

\section{Additional file 1: Ecological data for DPL continental comparison} model.

Additional file 2: Akaike Information Criteria (AIC values for the top ten candidate models that predict variation in annual mean DPL (continental scale).

Additional file 3: Akaike Information Criteria (AIC) values for the top ten candidate models that predict variation in DPL (local scale).

Additional file 4: Model testing variables predicting travel speed of baboon troops (local scale).

\section{Abbreviations}

CT: Camp Troop; MT: Matawi Troop; DPL: Day path length; GAM: Generalized additive model; LMM: Linear mixed model; AIC: Akaike's information criterion; PPI: Primary productivity index; GPS: Geographical positioning system; Pann: Average annual rainfall; Tann: Average annual temperature; PmoSD: Standard deviation across average monthly values for 12 months; TmoSD: Standard deviation across average monthly values for 12 months; $\mathrm{P}<100$ : Number of months with less than $100 \mathrm{~mm}$ of rainfall.

\section{Competing interests}

The authors declare that they have no competing interest.

\section{Authors' contributions}

CJ collected all Issa baboon ranging data with supervision from DF, AP and FS. AP and FS provided data on phenology, temperature and rainfall for Issa. $\mathrm{CJ}$ and AJK analysed the data and wrote the manuscript with input from all other authors. All authors read and approved the final manuscript.

\section{Acknowledgments}

We are grateful to the UCSD/Salk Center for Academic Research and Training in Anthropogeny (CARTA) for support for ongoing research at Issa, Ugalla. We thank the Tanzania Commission for Science and Technology (COSTECH) and Tanzania Wildlife Research Institute (TAWIRI) for permission to work in Ugalla, and to Busoti Juma, Msigwa Rashid, Joffrey Lucas, Shedrack Lucas, Ndai Samwely and Mlela Juma for their patience and hard work in conducting fieldwork. We also thank Rachel Noser, Russel Hill and Robin Dunbar for their correspondence and providing additional information and data used in our continental level analyses and Russell Hill, Emily Shepard and two anonymous reviewers for providing critical feedback on the manuscript. We are grateful to Ines Fürtbauer, Luca Börger, Tina Cornioley and Hannah Williams who all provided statistical advice. AJK was supported by a Natural Environment Research Council Fellowship (NE/H016600/3).

\section{Author details}

'Department of Biosciences, College of Science, Swansea University, Swansea, UK. ${ }^{2}$ Division of Biological Anthropology, Department of Archaeology and Anthropology, University of Cambridge, Cambridge, UK.

Received: 4 November 2014 Accepted: 20 April 2015

Published online: 01 July 2015

\section{References}

1. Garland T. Scaling the ecological cost of transport to body mass in terrestrial mammals. Am Nat. 1983;121:571-87.

2. Jetz W, Carbone C, Fulford J, Brown JH. The Scaling of Animal Space Use. Science. 2004;306:266-8.

3. Carbone C, Cowlishaw G, Isaac NJB, Rowcliffe JM, Url S. How Far Do Animals Go? Determinants of Day Range in Mammals. Am Nat. 2005;165:290-7.

4. Clutton-Brock T, Harvey P. Species Differences in Feeding and Ranging Behaviour in Primates. In: Clutton-Brock T, editor. Primate Ecol Stud Feed ranging Behav lemurs, monkeys apes. (London) Ltd: Academic Press Inc 1977. p. 557-79.

5. Isbell LA. Daily Ranging Behavior of Red Colobus (Colobus badius tephrosceles) in Kibale Forest, Uganda. Folia Primatol. 1983:41:34-48.

6. Li B, Chen C, Ji W, Ren B. Seasonal Home Range Changes of the Sichuan Snub-Nosed Monkey (Rhinopithecus roxellana) in the Oinling Mountains of China. Folia Primatol. 2000;71:375-86.
7. Hemingway C, Bynum N, Brockman D, van Schaik C. The influence of seasonality on primate diet and ranging. In: Seas Primates. Cambridge: Cambridge University Press; 2005. p. 57-104.

8. Gerber BD, Arrigo-Nelson S, Karpanty SM, Kotschwar M, Wright PC. Spatial Ecology of the Endangered Milne-Edwards' Sifaka (Propithecus edwardsi): Do Logging and Season Affect Home Range and Daily Ranging Patterns? Int J Primatol. 2012;33:305-21.

9. Altmann SA. Baboons, Space, Time, and Energy. Integr Comp Biol. 1974;14:221-48.

10. Wahungu G. Common Use of Sleeping Sites by Two Primate Species in Tana River, Kenya. Afr J Ecol. 2001;39:18-23.

11. Barton R. Habitat use and resource availability in baboons. Anim Behav. 1992:43:831-44.

12. Harding R. Ranging Patterns of a Troop of Baboons (Papio anubis) in Kenya Folia Primatol. 1976:25:143-85.

13. Pebsworth P, Maclntosh A, Morgan HR, Huffman MA. Factors Influencing the Ranging Behavior of Chacma Baboons (Papio hamadryas ursinus) Living in a Human-Modified Habitat. Int J Primatol. 2012;33:872-87.

14. Coe M, Cumming D, Phillipson J. Biomass and production of large African herbivores in relation to rainfall and primary production. Oecologia. 1976;22:341-54

15. Deshmukh I. A common relationship between precipitation and grassland peak biomass for east and southern Africa. Afr J Ecol. 1984;22:181-6.

16. Van Schaik CP, Terborgh JW, Wright SJ. The Phenology of Tropical Forests: Adaptive Significance and Consequences for Primary Consumers. Annu Rev Ecol Syst. 1993;24:353-77.

17. Altmann SA, Altmann J. Baboon Ecology: African Field Research. Chicago: University of Chicago Press; 1970

18. Myneni RB, Hall FG, Sellers PJ, Marshak AL. The interpretation of spectral vegetation indexes. IEEE Trans Geosci Remote Sens. 1995;33:481-6.

19. Willems EP, Barton RA, Hill RA. Remotely sensed productivity, regional home range selection, and local range use by an omnivorous primate. Behav Ecol. 2009;20:985-92.

20. Clutton-Brock T, Harvey P. Home range size, population density and phylogeny in primates. Primate Ecol Hum Orig. 1979;32:201-214.

21. Isbell LA. Contest and scramble competition: patterns of female aggression and ranging behavior among primates. Behav Ecol. 1991;2:143-55.

22. Hoffman TS, O'Riain MJ. Troop size and human-modified habitat affect the ranging patterns of a chacma baboon population in the cape peninsula, South Africa. Am J Primatol. 2012;74:853-63.

23. Chapman CA, Chapman LJ, Wrangham RW. Ecological constraints on group size: an analysis of spider monkey and chimpanzee subgroups. Behav Ecol Sociobiol. 1995:36:59-70.

24. Dias LG, Strier KB. Effects of Group Size on Ranging Patterns in Brachyteles arachnoides hypoxanthus. Int J Primatol. 2003;24:209-21.

25. Doran-Sheehy D, Greer D, Mongo P, Schwindt D. Impact of ecological and social factors on ranging in western gorillas. Am J Primatol. 2004;64:207-22.

26. Ganas J, Robbins M. Ranging behavior of the mountain gorillas (Gorilla beringei beringei) in Bwindi Impenetrable National Park, Uganda: a test of the ecological constraints model. Behav Ecol Sociobiol. 2005;58:277-88.

27. Kingdon J. The Kingdon Field Guide to African Mammals. London: A \& C Black Publishers Ltd; 2003.

28. Stacey PB. Group size and foraging efficiency in yellow baboons. Behav Ecol Sociobiol. 1986;18:175-87.

29. Dunbar RIM. Time: a hidden constraint on the behavioural ecology of baboons. Behav Ecol Sociobiol. 1992;31:35-49.

30. Hill RA, Dunbar RIM. Climatic determinants of diet and foraging behaviour in baboons. Evol Ecol. 2002:16:579-93.

31. Bettridge C, Lehmann J, Dunbar RIM. Trade-offs between time, predation risk and life history, and their implications for biogeography: A systems modelling approach with a primate case study. Ecol Modell. 2010;221:777-90.

32. Korstjens AH, Lehmann J, Dunbar RIM. Resting time as an ecological constraint on primate biogeography. Anim Behav. 2010;79:361-74.

33. Bronikowski AM, Altmann J. Foraging in a variable environment: weather patterns and the behavioral ecology of baboons. Behav Ecol Sociobiol. 1996;39:11-25.

34. Chapman CA, Pavelka M. Group size in folivorous primates: ecological constraints and the possible influence of social factors. Primates. 2005:46:1-9.

35. Pettorelli N, Vik J, Mysterud A. Using the satellite-derived NDVI to assess ecological responses to environmental change. Trends Ecol Evol. 2005;20:503-10. 
36. Post D. Activity Patterns of Yellow Baboons (Papio cynocephalus) in the Amboseli National Park, Kenya. Anim Behav. 1981;29:357-74.

37. Sigg H, Stolba A. Home Range and Daily March in a Hamadryas Baboon Troop. Folia Primatol. 1981:36:40-75.

38. Sharman M. Feeding, ranging and social organisation of the guinea baboon. PhD thesis. New Haven, Connecticut, USA: Yale Univeristy; 1981.

39. Davidge C. Ecology of Baboons (Papio ursinus) at Cape Point. Zool Africana. 1978;13:329-50

40. Norton GW, Rhine R, Wynn GW, Wynn RD. Baboon Diet: A Five-Year Study of Stability and Variability in the Plant Feeding and Habitat of the Yellow Baboons (Papio cynocephalus) of Mikumi National Park, Tanzania. Folia Primatol. 1987:48:78-120.

41. Whiten A, Byrne RW, Barton R a, Waterman PG, Henzi SP. Dietary and foraging strategies of baboons. Philos Trans R Soc Lond. 1991;334:187-95.

42. Gaynor D. Foraging and feeding behaviour of chacma baboons in a woodland habitat. PhD thesis. KwaZulu-Natal, South Africa: University of Natal; 1994.

43. Swedell L. Ranging behavior, group size and behavioral flexibility in Ethiopian hamadryas baboons (Papio hamadryas hamadryas). Folia Primatol. 2002;73:95-103.

44. King AJ. Leadership, coordinated behaviour, and information use in a socia primate. PhD thesis. London, United Kingdom: University College London; 2008.

45. Schreier AL, Grove M. Ranging patterns of hamadryas baboons: random walk analyses. Anim Behav. 2010;80:75-87.

46. Markham AC. Temporal Landscape Partitioning among Baboon (Papio cynocephalus) Social Groups. Princeton, New Jersey, USA: Princeton University; 2012

47. Chapman CA, Chapman LJ. Determinants of Group Size in Primates: The Importance of Travel Costs. In: Boinski S, Garber P, editors. Move How Why Anim Travel Groups. Chicago: The University of Chicago Press; 2000. p. 24-7.

48. Pochron ST. Can Concurrent Speed and Directness of Travel Indicate Purposeful Encounter in the Yellow Baboons (Papio hamadryas cynocephalus) of Ruaha National Park, Tanzania? Int J Primatol. 2001;22:773-85.

49. Garber PA. Role of spatial memory in primate foraging patterns: Saguinus mystax and Saguinus fuscicollis. Am J Primatol. 1989;19:203-16.

50. Menzel C. Primates' knowledge of their natural habitat: as indicated in foraging. In: Whiten A, Byrne RW, editors. Machiavellian intellingence II extensions Eval. Cambridge: Cambridge University Press; 1997. p. 207-39.

51. Janson C. Experimental evidence for spatial memory in foraging wild capuchin monkeys, Cebus apella. Anim Behav. 1998;55:1229-43.

52. Pochron S. The Core Dry-Season Diet of Yellow Baboons (Papio hamadryas cynocephalus) in Ruaha National Park, Tanzania. Folia Primatol. 2000;71:346-9.

53. Sueur C. A non-Lévy random walk in chacma baboons: what does it mean? PLoS One. 2011;6:1-5.

54. Marshall A, Wrangham RW. Evolutionary consequences of fallback foods. Int J Primatol. 2007:28:1219-35.

55. Overdorff D. Ecological and reproductive correlates to range use in redbellied lemurs (Eulemur rubriventer) and rufous lemurs (Eulemur fulvus rufus). In: Lemur Soc Syst their Ecol basis. US: Springer; 1993. p. 167-78.

56. Cipolletta C. Effects of group dynamics and diet on the ranging patterns of a western gorilla group (Gorilla gorilla gorilla) at Bai Hokou, Central African Republic. Am J Primatol. 2004;64:193-205.

57. Grueter C, Li D, Ren B, Wei F. Fallback foods of temperate-living primates: A case study on snub-nosed monkeys. Am J Primatol. 2009:140:700-15.

58. McKey D, Waterman P. Ranging behaviour of a group of black colobus (Colobus satanas) in the Douala-Edea Reserve, Cameroon. Folia Primatol. 1982:39:264-304

59. Wieczkowski J. Examination of increased annual range of a Tana mangabey (Cercocebus galeritus) group. Am J Phys Anthropol. 2005;128:381-8.

60. Baoping R, Ming L, Yongcheng L, Fuwen W. Influence of day length, ambient temperature, and seasonality on daily travel distance in the Yunnan snub-nosed monkey at Jinsichang, Yunnan, China. Am J Primatol. 2009;71:233-41.

61. Stoltz L, Saayman G. Ecology and Behaviour of Baboons in the Northern Transvaal. Ann Transvaal Museum. 1970;26:99-143.

62. Lehmann J, Korstjens AH, Dunbar RIM. Fission-fusion social systems as a strategy for coping with ecological constraints: a primate case. Evol Ecol. 2007;21:613-34.
63. Houerou HL. Rain use efficiency: a unifying concept in arid-land ecology. J Arid Environ. 1984:7:213-47.

64. Willmott C, Matsuura K. Terrestrial air temperature and precipitation: monthly and annual climatologies (1950-1999). http://climate.geog. udel.edu/ climate/html_pages/README.ghcn_ts2.html. 2001.

65. Legates DR, Willmott CJ. Mean seasonal and spatial variability in global surface air temperature. Theor Appl Climatol. 1990;41:11-21.

66. Legates DR, Willmott CJ. Mean seasonal and spatial variability in gauge-corrected, global precipitation. Int J Climatol. 1990;10:111-27.

67. R Development Core Team. R: A language and environment for statistical computing. Version 3.1.1. 2010.

68. Tabachnick BG, Fidell LS. Using Multivariate Statistics. Oxford, United Kingdom: Pearson Education; 2012.

69. Akaike H. Information theory and an extension of the maximum likelihood principle. Sel Pap Hirotugu Akaike. Springer: New York; 1998;6710-624

70. Burnham KP, Anderson DR. Model selection and multimodel inference: a practical information-theoretic approach. Colorado State University, Fort Collins, USA: Springer Science \& Business Media; 2002.

71. Kuznetsova A. Tests for random and fixed effects for linear mixed effect models (Imer ojects of Ime4 package). R package version 2.0-6. 2012

72. Stewart FA. The Evolution of Shelter: Ecology and Ethology of Chimpanzee Nest Building. PhD thesis. Cambridge, United Kingdom: University of Cambridge; 2011.

73. Dunlap G, Shufeldt H, Annapolis M. Dutton's Navigation and Piloting 12th ed. USA: United States Naval Institute and Piloting; 1972.

74. Benhamou S. How to reliably estimate the tortuosity of an animal's path: straightness, sinuosity, or fractal dimension? J Theor Biol. 2004;229:209-20.

75. Calenge $\mathrm{C}$. The package adehabitat for the $\mathrm{R}$ software: a tool for the analysis of space and habitat use by animals. Ecol Modell. 2006;197:516-9.

76. Ransom TW. Diet and Feeding Behaviour. In: Candland D, editor. Beach Troop of the Gombe. Lewisburg: Bucknell University Press; 1981. p. 63-72.

77. Rasmussen D. Environmental and behavioral correlates of changes in range use in a troop of yellow (Papio cynocephalus) and a troop of olive (P. anubis) baboons. Anim Behav. 1978;31:834-56.

78. Depew L. Ecology and behaviour of baboons (Papio anubis) in the Shai Hills Game Production Reserve, Ghana. Cape Coast, Central Region, Ghana: Cape Coast University; 1983.

79. Barton R. Foraging strategies, diet and competition in olive baboons. PhD thesis. St Andrews, Fife, Scotland: University of St Andrews; 1989.

80. Dunbar RIM, Dunbar E. Ecological Relations and Niche Separation between Sympatric Terrestrial Primates in Ethiopia. Folia Primatol. 1974;21:36-60.

81. Chapman CA, Wrangham RW, Chapman LJ. Indices of Habitat-wide Fruit Abundance in Tropical Forests. Biotropica. 1994;26:160-71.

82. Head JS, Boesch C, Makaga L, Robbins MM. Sympatric Chimpanzees (Pan troglodytes troglodytes) and Gorillas (Gorilla gorilla gorilla) in Loango National Park, Gabon: Dietary Composition, Seasonality, and Intersite Comparisons. Int J Primatol. 2011:32:755-75.

83. Anderson DP, Nordheim EV, Moermond TC, Bi ZBG, Boesch C. Factors Influencing Tree Phenology in Tai National Park, Cote d'Ivoire. Biotropica. 2005;37:631-40.

84. Yamagiwa J, Basabose AK. Diet and seasonal changes in sympatric gorillas and chimpanzees at Kahuzi-Biega National Park. Primates. 2006:47:74-90.

85. Nkurunungi JB, Ganas J, Robbins MM, Stanford CB. A comparison of two mountain gorilla habitats in Bwindi Impenetrable National Park, Uganda. Afr J Ecol. 2004:42:289-97.

86. Hastie TJ, Tibshirani RJ. Generalized additive models. Stat Sci. 1986;1:297-318

87. Hill RA. Thermal constraints on activity scheduling and habitat choice in baboons. Am J Phys Anthropol. 2006;129:242-9.

88. Fischer R, Turner N. Plant productivity in the arid and semiarid zones. Annu Rev Plant Physiol. 1978;29:277-317.

89. Brennan EJ, Else JG, Altmann J. Ecology and behaviour of a pest primate: vervet monkeys in a tourist-lodge habitat. Afr J Ecol. 1985;23:35-44.

90. Hill C. People, crops, and primates: a conflict of interest. In: Patterson J, Williams J, Wolfe L, editors. Commensalism confl human-primate interface. Norman, Oklahoma, USA: The American Society of Primatologists; 2005.

91. Siemers B. Seasonal variation in food resource and forest strata use by brown capuchin monkeys (Cebus apella) in a disturbed forest fragment. Folia Primatol. 2000;71:181-4.

92. Altmann J. Differences in daily life between semi provisioned and wild-feeding baboons. Am J Primatol. 1988;15:213-21.

93. Saj T, Sicotte P, Paterson JD. Influence of Human Food Consumption on the Time Budget of Vervets. Int J Primatol. 1999;20:977-94. 
94. Strum SC. The Development of Primate Raiding: Implications for Management and Conservation. Int J Primatol. 2010;31:133-56.

95. Chapman CA. Ecological Constraints on Group Size in Three Species of Neotropical Primates. Folia Primatol. 1990:55:1-9.

96. Precht H, Brück K. Temperature and Life. Berlin: Springer; 1973.

97. Hiley PG. The thermoreculatory responses of the galago (Galago crassicaudatus), the baboon (Papio cynocephalus) and the chimpanzee (Pan stayrus) to heat stress. J Physiol. 1976;254:657-71.

98. Brain C, Mitchell D. Body Temperature Changes in Free-ranging Baboons (Papio hamadryas ursinus) in the Namib Desert, Namibia. Int J Primatol. 1999;20:585-98

99. Stelzner JK. Thermal Effects on Movement Patterns of Yellow Baboons. Primates. 1988;29:91-105.

100. Pochron ST. Sun avoidance in the yellow baboons (Papio cynocephalus cynocephalus) of Ruaha National Park, Tanzania. Variations with season, behavior and weather. Int J Biometeorol. 2000;44:141-7.

101. Noser R, Byrne RW. Travel routes and planning of visits to out-of-sight resources in wild chacma baboons, Papio ursinus. Anim Behav. 2007:73:257-66.

102. Lehmann J, Korstjens AH, Dunbar RIM. Time management in great apes: implications for gorilla biogeography. Evol Ecol Res. 2008;10:517-36.

103. Hernandez-Aguilar RA. Ecology and Nesting Patterns of Chimpanzees in Issa, Ugalla, Western Tanzania. PhD thesis. Los Angeles California, USA: University of Southern California; 2006.

104. Cowlishaw G. Trade-offs between foraging and predation risk determine habitat use in a desert baboon population. Anim Behav. 1997;53:667-86.

105. Hall K. Numerical data, maintenance activities and locomotion of the wild chacma baboon, Papio ursinus. Proc Zool Soc London. 1962;139:181-220.

106. Anderson J. Ethology and ecology of sleep in monkeys and apes. Adv Study Behav. 1984;14:165-230.

107. Willems EP, Hill RA. Predator-specific landscapes of fear and resource distribution: effects on spatial range use. Ecology. 2009;90:546-55.

108. Cowlishaw $\mathrm{G}$. Refuge use and predation risk in a desert baboon population. Anim Behav. 1997;54:241-53.

109. Cowlishaw G. Vulnerability to predation in baboon populations. Behaviour. 1994;131:293-304

110. Stewart FA, Pruetz JD. Do chimpanzee nests serve an anti-predatory function? Am J Primatol. 2013;75:593-604

111. Swedell L. African Papionins: Diversity of Social Organization and Ecological Flexibility. In: Campbell C, Fuentes A, MacKinnon K, Panger M, Bearder S, Stumpf R, editors. Primates Perspect. 2nd ed. New York: Oxford University Press; 2011. p. 241-77.

112. Kaplan BS, O'Riain MJ, van Eeden R, King AJ. A Low-Cost Manipulation of Food Resources Reduces Spatial Overlap Between Baboons (Papio ursinus) and Humans in Conflict. Int J Primatol. 2011;32:1397-412.

113. Patterson J. Variations in ecology and adaptation of Ugandan baboons. PhD thesis. Toronto, Ontario, Canada: University of Toronto; 1976.

114. Warren Y, Higham J, Maclarnon A, Ross C. Crop-raiding and Commensalism in Olive Baboons: The Costs and Benefits of Living with Humans. In: Sommer V, Ross C, editors. Primates Gashaka Socieoecology Conserv Niger Biodivers Hotspot. New York: Springer; 2011. p. 307-32.

115. Rowell T. Forest living baboons in Uganda. J Zool. 1966;149:344-64.

116. Aldrich-Blake F, Bunn T. Observations on baboons, Papio anubis, in an arid region in Ethiopia. Folia Primatol. 1971;15:1-35.

117. Post D. Feeding and ranging behavior of the yellow baboon (Papio cynocephalus). PhD thesis. New Haven, Connecticut, USA: Yale University; 1978.

118. Wahungu G. Diet and Habitat Overlap in Two Sympatric Primate Species, the Tana crested mangabey Cercocebus galeritus and yellow baboon Papio cynocephalus. Afr J Ecol. 1998;36:159-73.

119. Nagel U. A Comparison of Anubis Baboons, Hamadryas Baboons and Their Hybrids at a Species Border in Ethiopia. Folia Primatol. 1973;19:104-65.

120. Kummer H. Social Organization of Hamadryas Baboons; a Field Study. Chicago: Chicago University Press; 1968

121. Hoffman TS, O'Riain MJ. The Spatial Ecology of Chacma Baboons (Papio ursinus) in a Human-modified Environment. Int J Primatol. 2010;32:308-28.
122. Whiten A, Byrne RW, Henzi SP. The behavioral ecology of mountain baboons. Int J Primatol. 1987:8:367-88.

123. Hill RA. Ecological and demographic determinants of time budgets in baboons: implications for cross-populational models of baboon socioecology. PhD thesis. Liverpool, United Kingdom: University of Liverpool; 1999.

124. Anderson C. Intertroop relations of chacma baboon (Papio ursinus). Int J Primatol. 1981;73(2):241-50.

125. Seyfarth RM. Social behaviour of adult baboons. PhD Thesis. Cambridge, United Kingdom: University of Cambridge; 1976.

\section{Submit your next manuscript to BioMed Central and take full advantage of:}

- Convenient online submission

- Thorough peer review

- No space constraints or color figure charges

- Immediate publication on acceptance

- Inclusion in PubMed, CAS, Scopus and Google Scholar

- Research which is freely available for redistribution 